\title{
Prediction on Droplet Sauter Mean Diameter in Gas-Liquid Mist Flow Based on Droplet Fractal Theory
}

\author{
Jian-Yi Liu, Xiao-Hua Tan, Zhou Fan, Xu-Tao You, Zhou Li, and Jia-Hui Zhao \\ State Key Laboratory of Oil and Gas Reservoir Geology and Exploitation, Southwest Petroleum University, Xindu Road 8, \\ Chengdu 610500, China
}

Correspondence should be addressed to Xiao-Hua Tan; xiaohua-tan@163.com

Received 14 March 2015; Revised 4 August 2015; Accepted 9 August 2015

Academic Editor: Carla Faraci

Copyright (c) 2015 Jian-Yi Liu et al. This is an open access article distributed under the Creative Commons Attribution License, which permits unrestricted use, distribution, and reproduction in any medium, provided the original work is properly cited.

We present a fractal model for droplet Sauter mean diameter in gas-liquid mist flow, based on the droplet fractal theory and the balance relationship between total droplet surface energy and total gas turbulent kinetic energy. The present model is expressed as functions of the droplet fractal dimension, gas superficial velocity, liquid superficial velocity, and other fluid characteristics. Agreement between the present model predictions and experimental measurements is obtained. Results verify the reliability of the present model.

\section{Introduction}

Droplet coalescence and breakup phenomena have obtained extensive attention in many physical and chemical process applications, that is, distillation, liquid-liquid extraction, emulsification, gas absorption, and multiphase reactions [13]. A lot of studies have shown that the tendency toward droplet coalescence or breakup depends on droplet size $[4,5]$. Although a number of equations have been proposed to predict the effect of appropriate parameters on drop sizes, they are semiempirical [6-10].

Shavit and Chigier [11] firstly observed the droplet fractal characteristics in droplet separation and jet. Zhou et al. [12] measured the droplet fractal dimensions and studied the relationship between the fractal characteristics and droplet distribution. Zhou and Yu [13] proposed a multifractal model to describe droplet dissolution characteristics and verified this model using experimental result. Apte et al. [14] established a stochastic subgrid model for large-eddy simulation of atomizing spray. Gorokhovski and Saveliev [15] proposed a numerical method to describe stochastically droplet production and developed a droplet distribution model based on studying the breakup of droplets at the large Weber number. Liu et al. [16] introduced a finite stochastic breakup model for air-blast atomizers based on the selfsimilarity of droplet breakup theory.

\section{Model}

Azzopardi [17] and Andreussi et al. [18], however, found that the droplet diameter of liquid carried through gas flow was associated with the liquid rate of gas flow. Thus, droplet diameter could increase with the increase of liquid rate at a given gas flow rate. According to Taitel et al. [19], under bubble flow conditions, when the turbulent force of the liquid phase was strong enough to overcome gas-liquid interfacial tension, the turbulent force will reduce the gas phase into small gas bubbles. Similarly, in mist flow, the liquid phase is dispersed into spherical liquid droplets in gas flow. That is to say, there exist two types of mutual resistance imposed on liquid droplets: turbulent force, which breaks droplets, and surface tension, which keeps droplets intact (Figure 1).

It has been shown that the cumulative size distributions of liquid droplets whose sizes are greater than or equal to $\lambda$ have been proven to follow the fractal scaling law [20,21]:

$$
N(L \geq \lambda)=\left(\frac{\lambda_{\max }}{\lambda}\right)^{D_{\mathrm{f}}}
$$

where $\lambda_{\max }$ is the maximum droplet diameter. $D_{\mathrm{f}}$ is the droplet fractal dimension, $0<D_{\mathrm{f}}<2$ in two-dimensional space, and $0<D_{\mathrm{f}}<3$ in three-dimensional space. 


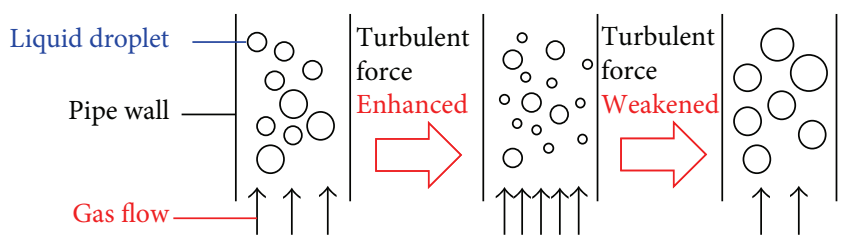

FIGURE 1: Relationship between liquid droplet diameter and turbulent force.

Equation (1) can be approximately considered as a continuous and differentiable function. Solving the differential of (1), the liquid droplet number between $\lambda$ and $\lambda+d \lambda$ can be obtained $[22,23]$ :

$$
-d N=D_{\mathrm{f}} \lambda_{\max }^{D_{\mathrm{f}}} \lambda^{-\left(D_{\mathrm{f}}+1\right)} d \lambda
$$

The negative variable in (2) indicates that liquid droplet number increases along with a decrease in droplet size [24], and $-d N>0$.

Droplet Sauter mean diameter is defined as [25]

$$
\lambda_{32}=\frac{-\int_{\lambda_{\min }}^{\lambda_{\max }} \lambda^{3} d N}{-\int_{\lambda_{\min }}^{\lambda_{\max }} \lambda^{2} d N} .
$$

The numerator term of (3) can be expressed based on droplet fractal theory [26]:

$$
-\int_{\lambda_{\min }}^{\lambda_{\max }} \lambda^{3} d N=\frac{D_{\mathrm{f}} \lambda_{\max }^{3}}{\left(3-D_{\mathrm{f}}\right)}\left[1-\left(\frac{\lambda_{\min }}{\lambda_{\max }}\right)^{3-D_{\mathrm{f}}}\right] .
$$

In gas-liquid mist flow real situation, $\lambda_{\min } / \lambda_{\max }<10^{-6}$, and $D_{\mathrm{f}}$ is greater than 0.5 , so $\left(\lambda_{\min } / \lambda_{\max }\right)^{3-D_{\mathrm{f}}}<10^{-3}$, and (4) can be simplified as [27]

$$
-\int_{\lambda_{\min }}^{\lambda_{\max }} \lambda^{3} d N=\frac{D_{\mathrm{f}} \lambda_{\max }^{3}}{\left(3-D_{\mathrm{f}}\right)} .
$$

Similarly, the denominator term of (3) can be expressed based on droplet fractal theory:

$$
-\int_{\lambda_{\min }}^{\lambda_{\max }} \lambda^{2} d N=\frac{D_{\mathrm{f}} \lambda_{\max }^{2}}{\left(2-D_{\mathrm{f}}\right)} .
$$

Substituting (5) and (6) into (3), the relationship between the droplet Sauter mean diameter and the maximum droplet diameter in gas-liquid mist flow can be solved:

$$
\lambda_{32}=\frac{\left(2-D_{\mathrm{f}}\right)}{\left(3-D_{\mathrm{f}}\right)} \lambda_{\max } .
$$

According to the balance between the surface energy of the dispersed liquid droplets and the turbulent kinetic energy of the continuous gas flow, the Droplet Sauter mean diameter can be derived.

In gas-liquid mist flow, the relationship between liquid velocity, $v_{1}$, and liquid superficial velocity, $v_{\mathrm{sl}}$, is [28]

$$
v_{\mathrm{sl}}=\frac{A_{1}}{A} v_{1},
$$

where

$$
\begin{aligned}
A & =\frac{\pi D^{2}}{4}, \\
A_{1} & =\frac{\pi D_{\mathrm{f}} \lambda_{\max }^{2}}{4\left(2-D_{\mathrm{f}}\right)} .
\end{aligned}
$$

The total free surface energy of dispersed droplets in continuous gas flow is

$$
E_{\mathrm{S}}=-v_{\mathrm{l}} \sigma \int_{\lambda_{\min }}^{\lambda_{\max }} \pi \lambda d N=\frac{\pi D_{\mathrm{f}} \nu_{1} \sigma \lambda_{\max }}{\left(1-D_{\mathrm{f}}\right)} .
$$

It can be seen that the value of the droplet fractal dimension is $0<D_{\mathrm{f}}<1$, when the total free surface energy of the dispersed droplets is greater than $0, E_{S}>0$.

Substituting (7) and (8) into (10), the total free surface energy of dispersed droplets in continuous gas flow can be expressed by droplet Sauter mean diameter using fractal theory:

$$
E_{\mathrm{S}}=\frac{\pi \sigma\left(2-D_{\mathrm{f}}\right)^{2} D^{2}}{\left(1-D_{\mathrm{f}}\right)\left(3-D_{\mathrm{f}}\right) \lambda_{32}} v_{\mathrm{sl}} .
$$

The total turbulent kinetic energy of gas-liquid mist flow can be expressed [29]:

$$
E_{\mathrm{T}}=\frac{3}{16} \pi f_{\mathrm{sg}} \rho_{\mathrm{g}} A D^{2} v_{\mathrm{sg}}^{3} .
$$

Total surface free energy of droplets in gas flow and the turbulent kinetic energy of gas are balanced $[30,31]$ :

$$
E_{\mathrm{S}}=E_{\mathrm{T}} \text {. }
$$

Substituting (11) and (12) into (13), droplet Sauter mean diameter can be obtained based on the balance between the surface energy of the dispersed liquid droplets and the turbulent kinetic energy of the continuous gas flow:

$$
\lambda_{32}=\frac{16 \sigma v_{\mathrm{sl}}\left(2-D_{\mathrm{f}}\right)^{2}}{3 f_{\mathrm{sg}} \rho_{\mathrm{g}}\left(1-D_{\mathrm{f}}\right)\left(3-D_{\mathrm{f}}\right) v_{\mathrm{sg}}^{3}} .
$$

Equation (14) cannot be directly solved by gas superficial velocity, $v_{\text {sg }}$, and liquid superficial velocity, $v_{\text {sl }}$, because droplet Sauter mean diameter, $\lambda_{32}$, and the droplet fractal dimension, $D_{\mathrm{f}}$, are unknown parameters.

Based on mist flow characteristics, maximum droplet diameter can be expressed as [28]

$$
\lambda_{\max }=\left[\frac{\left(2-D_{\mathrm{f}}\right) D^{2} v_{\mathrm{sl}}}{D_{\mathrm{f}}\left(v_{\mathrm{sg}}+v_{\mathrm{sl}}\right)}\right]^{1 / 2} .
$$

Substituting (7) into (15), droplet Sauter mean diameter based on mist flow characteristics can be solved:

$$
\lambda_{32}=\left[\frac{v_{\mathrm{sl}} D^{2}\left(2-D_{\mathrm{f}}\right)^{3}}{D_{\mathrm{f}}\left(v_{\mathrm{sg}}+v_{\mathrm{sl}}\right)\left(3-D_{\mathrm{f}}\right)^{2}}\right]^{1 / 2} .
$$


Substituting (14) into (16), the fractal expression for droplet Sauter mean diameter under gas-liquid mist flow conditions can be obtained:

$$
\begin{aligned}
\lambda_{32} & =\frac{16 \sigma v_{\mathrm{sl}}\left(2-D_{\mathrm{f}}\right)^{2}}{3 f_{\mathrm{sg}} \rho_{\mathrm{g}}\left(1-D_{\mathrm{f}}\right)\left(3-D_{\mathrm{f}}\right) v_{\mathrm{sg}}^{3}}, \\
D_{\mathrm{f}} & =\frac{-B-\sqrt{B^{2}-4 A C}}{2 A},
\end{aligned}
$$

where

$$
\begin{aligned}
& A=\left(3 D f_{\mathrm{sg}} \rho_{\mathrm{g}} v_{\mathrm{sg}}^{3}\right)^{2}+256 v_{\mathrm{sg}} v_{\mathrm{sl}} \sigma^{2}+256\left(v_{\mathrm{sl}} \sigma\right)^{2}, \\
& B=-2\left[\left(3 D f_{\mathrm{sg}} \rho_{\mathrm{g}} v_{\mathrm{sg}}^{3}\right)^{2}+256 v_{\mathrm{sg}} v_{\mathrm{sl}} \sigma^{2}+256\left(v_{\mathrm{sl}} \sigma\right)^{2}\right], \\
& C=\left(3 D f_{\mathrm{sg}} \rho_{\mathrm{g}} v_{\mathrm{sg}}^{3}\right)^{2}
\end{aligned}
$$

Equation (17) is the analytical solution for droplet Sauter mean diameter in gas-liquid mist flow. The droplet Sauter mean diameter, $\lambda_{32}$, and the droplet fractal dimension, $D_{\mathrm{f}}$, can be simultaneously solved using gas superficial velocity, $v_{\mathrm{sg}}$, and liquid superficial velocity, $v_{\mathrm{sl}}$. In this model, we explained the relationship between the droplet Sauter mean diameter and the gas-liquid mist flow situation based on the energy balance theory. When the gas superficial velocity, $v_{\mathrm{sg}}$, increases, the turbulent kinetic energy of gas, $E_{\mathrm{T}}$, increases. Because of the energy balance, the total surface free energy of droplets in gas flow, $E_{S}$, needs to increase too, which means the liquid phase has to divide into more droplets, leading to the increase of the surface between gas phase and liquid phase. That change of flow situation makes the droplet fractal dimension, $D_{\mathrm{f}}$, be larger and droplet Sauter mean diameter, $\lambda_{32}$, be smaller. This is consistent with the physical situation.

\section{Results and Discussion}

Figure 2 shows a comparison between experimental results (solid points) measured by Fore and Dukler [32] and the present model predictions (full lines). The parameters $\sigma=$ $0.072 \mathrm{~N} / \mathrm{m}$ and $\mu_{1}=1.05 \times 10^{-3} \mathrm{~Pa} \cdot \mathrm{s}$ are used in this experiment. It can be seen that droplet Sauter mean diameter decreases with an increase in gas superficial velocity, $v_{\mathrm{sg}}$, and increases with an increase in liquid superficial velocity, $v_{\mathrm{sl}}$. This is because when $v_{\mathrm{sg}}$ increases, the total turbulent kinetic energy increases, making droplet breakup into smaller droplet. And when the $v_{\mathrm{sl}}$ increases, the total free surface energy increases, making droplet coalescence into bigger droplet. Agreement between the predictions and the experimental results in different liquid viscosity and superficial velocity conditions is obtained. Results suggest that the present droplet Sauter mean diameter model is reliable.

\section{Conclusion}

Based on the droplet fractal theory and the balance relationship between total droplet surface energy and total gas turbulent kinetic energy, the fractal expression for droplet Sauter mean diameter in gas-liquid mist flow is derived. Agreement

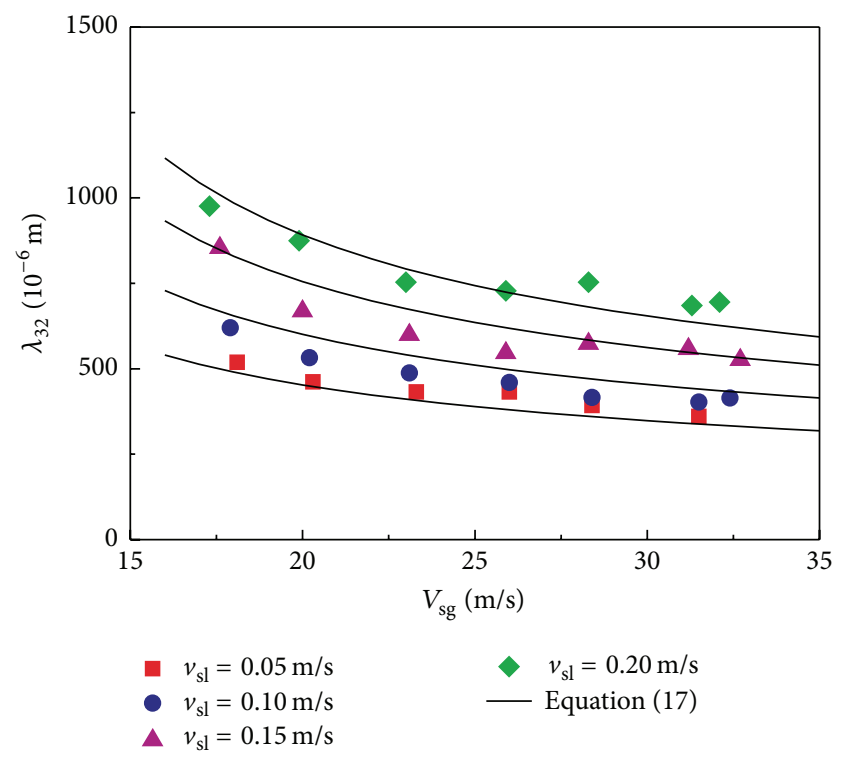

FIGURE 2: Comparison between experimental results and present model predictions.

between the present model predictions and experimental measurements is obtained. Results verify the reliability of the present model.

\section{Nomenclature}

A: Cross-sectional area of a conduit, $\mathrm{m}^{2}$

$A_{1}$ : Cross-sectional area occupied by liquid, $\mathrm{m}^{2}$

$D$ : $\quad$ Conduit diameter, $\mathrm{m}$

$D_{\mathrm{f}}$ : Droplet fractal dimensions

$E_{S}$ : Total surface free energy, $\mathrm{W}$

$E_{\mathrm{T}}$ : Total turbulent kinetic energy, $\mathrm{W}$

$N$ : $\quad$ Fractal accumulative droplet number

$v_{1}: \quad$ Liquid velocity, $\mathrm{m} / \mathrm{s}$

$v_{\mathrm{sg}}$ : Gas superficial velocity, $\mathrm{m} / \mathrm{s}$

$v_{\mathrm{sl}}: \quad$ Liquid superficial velocity, $\mathrm{m} / \mathrm{s}$

$\lambda: \quad$ Droplet diameter, $\mathrm{m}$

$\lambda_{\max }:$ Maximum droplet diameter, $\mathrm{m}$

$\lambda_{\min }$ : Minimum droplet diameter, $\mathrm{m}$

$\lambda_{32}$ : Droplet Sauter mean diameter

$\rho_{\mathrm{g}}: \quad$ Gas density, $\mathrm{kg} / \mathrm{m}^{3}$

$\rho_{l}: \quad$ Liquid density, $\mathrm{kg} / \mathrm{m}^{3}$

$\sigma: \quad$ Interfacial tension, $\mathrm{N} / \mathrm{m}$.

\section{Subscripts}

g: Gas phase

1: Liquid phase

s: Superficial

T: Turbulent.

\section{Conflict of Interests}

The authors declare that there is no conflict of interests regarding the publication of this paper. 


\section{Acknowledgments}

The authors are grateful for financial support from the National Science Fund for Distinguished Young Scholars of China (51125019), the National Natural Science Foundation of China (51474181), and the 2014 Australia China Natural Gas Technology Partnership Fund Top Up Scholarship.

\section{References}

[1] S. Ceylan, G. Kelbaliyev, and K. Ceylan, "Estimation of the maximum stable drop sizes, coalescence frequencies and the size distributions in isotropic turbulent dispersions," Colloids and Surfaces A: Physicochemical and Engineering Aspects, vol. 212, no. 2-3, pp. 285-295, 2003.

[2] R. Shu, W. Sun, T. Wang, C. Wang, X. Liu, and Z. Tong, "Linear and nonlinear viscoelasticity of water-in-oil emulsions: effect of droplet elasticity," Colloids and Surfaces A: Physicochemical and Engineering Aspects, vol. 434, pp. 220-228, 2013.

[3] Y. Y. Tarasevich, I. V. Vodolazskaya, and O. P. Bondarenko, "Modeling of spatial-temporal distribution of the components in the drying sessile droplet of biological fluid," Colloids and Surfaces A: Physicochemical and Engineering Aspects, vol. 432, pp. 99-103, 2013.

[4] N. Vankova, S. Tcholakova, N. D. Denkov, I. B. Ivanov, V. D. Vulchev, and T. Danner, "Emulsification in turbulent flow: 1. Mean and maximum drop diameters in inertial and viscous regimes," Journal of Colloid and Interface Science, vol. 312, no. 2, pp. 363-380, 2007.

[5] G. T. Vladisavljević, I. Kobayashi, and M. Nakajima, "Effect of dispersed phase viscosity on maximum droplet generation frequency in microchannel emulsification using asymmetric straight-through channels," Microfluidics and Nanofluidics, vol. 10, no. 6, pp. 1199-1209, 2011.

[6] D. F. Tatterson, J. C. Dallman, and T. J. Hanratty, "Drop sizes in annular gas-liquid flows," AIChE Journal, vol. 23, no. 1, pp. 68-76, 1977.

[7] P. Andreussi, G. Romano, and S. Zanelli, "Drop size distribution in annular mist flow," in Proceedings of the 1st Conference on Liquid Atomization and Spray Systems, Tokyo, Japan, 1978.

[8] B. J. Azzopardi, A. Piearcey, and D. M. Jepson, "Drop size measurements for annular two-phase flow in a $20 \mathrm{~mm}$ diameter vertical tube," Experiments in Fluids, vol. 11, no. 2-3, pp. 191-197, 1991.

[9] J. C. B. Lopes and A. E. Dukler, "Droplet sizes, dynamics and deposition in vertical annular flow," Tech. Rep., NTIS, 1985.

[10] G. Kocamustafaogullari, S. Smits, J. Razi, and W. Huang, "Droplet size modelling in annular flow," in Proceedings of the 6th International Topical Meeting on Nuclear Reactor Thermal Hydraulics, 1993.

[11] U. Shavit and N. Chigier, "Fractal dimensions of liquid jet interface under breakup," Atomization and Sprays, vol. 5, no. 6, pp. 525-543, 1995.

[12] W. Zhou, T. Zhao, T. Wu, and Z. Yu, "Application of fractal geometry to atomization process," Chemical Engineering Journal, vol. 78, no. 2-3, pp. 193-197, 2000.

[13] W.-X. Zhou and Z.-H. Yu, "Multifractality of drop breakup in the air-blast nozzle atomization process," Physical Review E, vol. 63, no. 1, Article ID 016302, 6 pages, 2000.
[14] S. V. Apte, M. Gorokhovski, and P. Moin, "LES of atomizing spray with stochastic modeling of secondary breakup," International Journal of Multiphase Flow, vol. 29, no. 9, pp. 1503-1522, 2003.

[15] M. A. Gorokhovski and V. L. Saveliev, "Analyses of Kolmogorov's model of breakup and its application into Lagrangian computation of liquid sprays under air-blast atomization," Physics of Fluids, vol. 15, no. 1, pp. 184-192, 2003.

[16] H.-F. Liu, X. Gong, W.-F. Li, F.-C. Wang, and Z.-H. Yu, "Prediction of droplet size distribution in sprays of prefilming air-blast atomizers," Chemical Engineering Science, vol. 61, no. 6, pp. 1741-1747, 2006.

[17] B. J. Azzopardi, "Drops in annular two-phase flow," International Journal of Multiphase Flow, vol. 23, no. 7, pp. 1-53, 1997.

[18] P. Andreussi, G. Romano, and S. Zanelli, "Drop size distribution in annular mist flow," in Proceedings of the 1st Conference on Liquid Atomisation in Spray Systems, Tokyo, Japan, 1978.

[19] Y. Taitel, D. Bornea, and A. E. Dukler, "Modelling flow pattern transitions for steady upward gas-liquid flow in vertical tubes," AIChE Journal, vol. 26, no. 3, pp. 345-354, 1980.

[20] X.-H. Tan, X.-P. Li, J.-Y. Liu, L.-H. Zhang, and Z. Fan, "Study of the effects of stress sensitivity on the permeability and porosity of fractal porous media," Physics Letters A, 2015.

[21] J. Cai, E. Perfect, C.-L. Cheng, and X. Hu, "Generalized modeling of spontaneous imbibition based on hagen-poiseuille flow in tortuous capillaries with variably shaped apertures," Langmuir, vol. 30, no. 18, pp. 5142-5151, 2014.

[22] X.-H. Tan, J.-Y. Liu, X.-P. Li, L.-H. Zhang, and J. Cai, "A simulation method for permeability of porous media based on multiple fractal model," International Journal of Engineering Science, vol. 95, pp. 76-84, 2015.

[23] J.-C. Cai, "A fractal approach to low velocity non-Darcy flow in a low permeability porous medium," Chinese Physics B, vol. 23, no. 4, Article ID 044701, 2014.

[24] M.-J. Yuan, B.-M. Yu, W. Zheng, and J. Yuan, "Fractal analysis of Casson fluid flow in porous media," Acta Physica Sinica, vol. 60, no. 2, Article ID 024703, 2011.

[25] A. W. Adamson, Physical Chemistry of Surfaces, John Wiley \& Sons, New York, NY, USA, 1990.

[26] J. Cai and S. Sun, "Fractal analysis of fracture increasing spontaneous imbibition in porous media with gas-saturated," International Journal of Modern Physics C, vol. 24, no. 8, Article ID 1350056, 2013.

[27] X.-H. Tan, X.-P. Li, J.-Y. Liu, L.-H. Zhang, and J. Cai, "Fractal analysis of stress sensitivity of permeability in porous media," Fractals, vol. 23, no. 2, Article ID 1550001, 2015.

[28] X.-H. Tan, J.-Y. Liu, X.-P. Li, G.-D. Zhang, and C. Tang, "A fractal model for the maximum droplet diameter in gas-liquid mist flow," Mathematical Problems in Engineering, vol. 2013, Article ID 532638, 6 pages, 2013.

[29] X.-H. Tan, X.-P. Li, and J.-Y. Liu, "Model of continuous liquid removal from gas wells by droplet diameter estimation," Journal of Natural Gas Science and Engineering, vol. 15, pp. 8-13, 2013.

[30] X. T. Chen, X. D. Cai, and J. P. Brill, "A general model for transition to dispersed bubble flow," Chemical Engineering Science, vol. 52, no. 23, pp. 4373-4380, 1997.

[31] N. Brauner, "The prediction of dispersed flows boundaries in liquid-liquid and gas-liquid systems," International Journal of Multiphase Flow, vol. 27, no. 5, pp. 885-910, 2001.

[32] L. B. Fore and A. E. Dukler, "The distribution of drop size and velocity in gas-liquid annular flow," International Journal of Multiphase Flow, vol. 21, no. 2, pp. 137-149, 1995. 


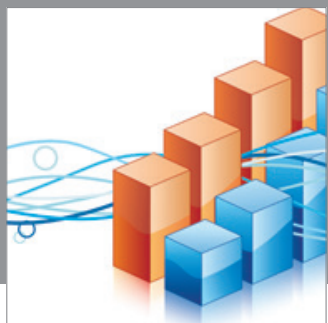

Advances in

Operations Research

mansans

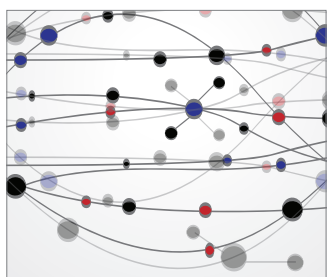

The Scientific World Journal
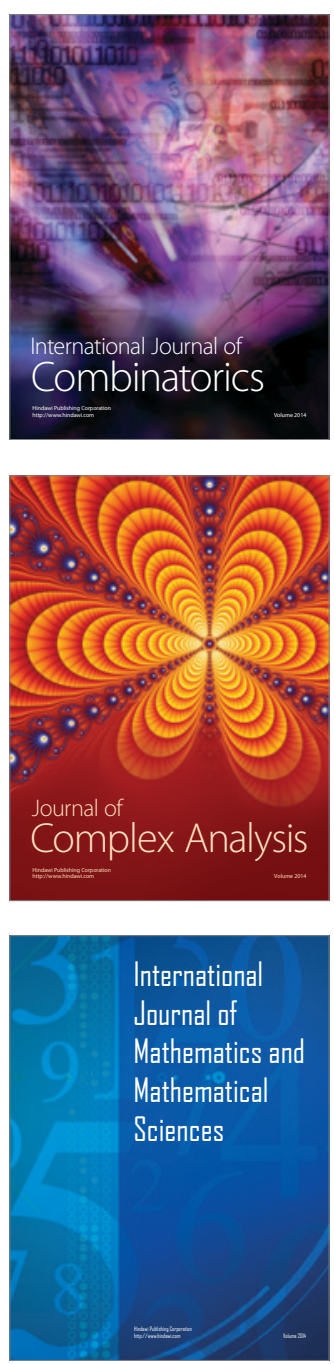
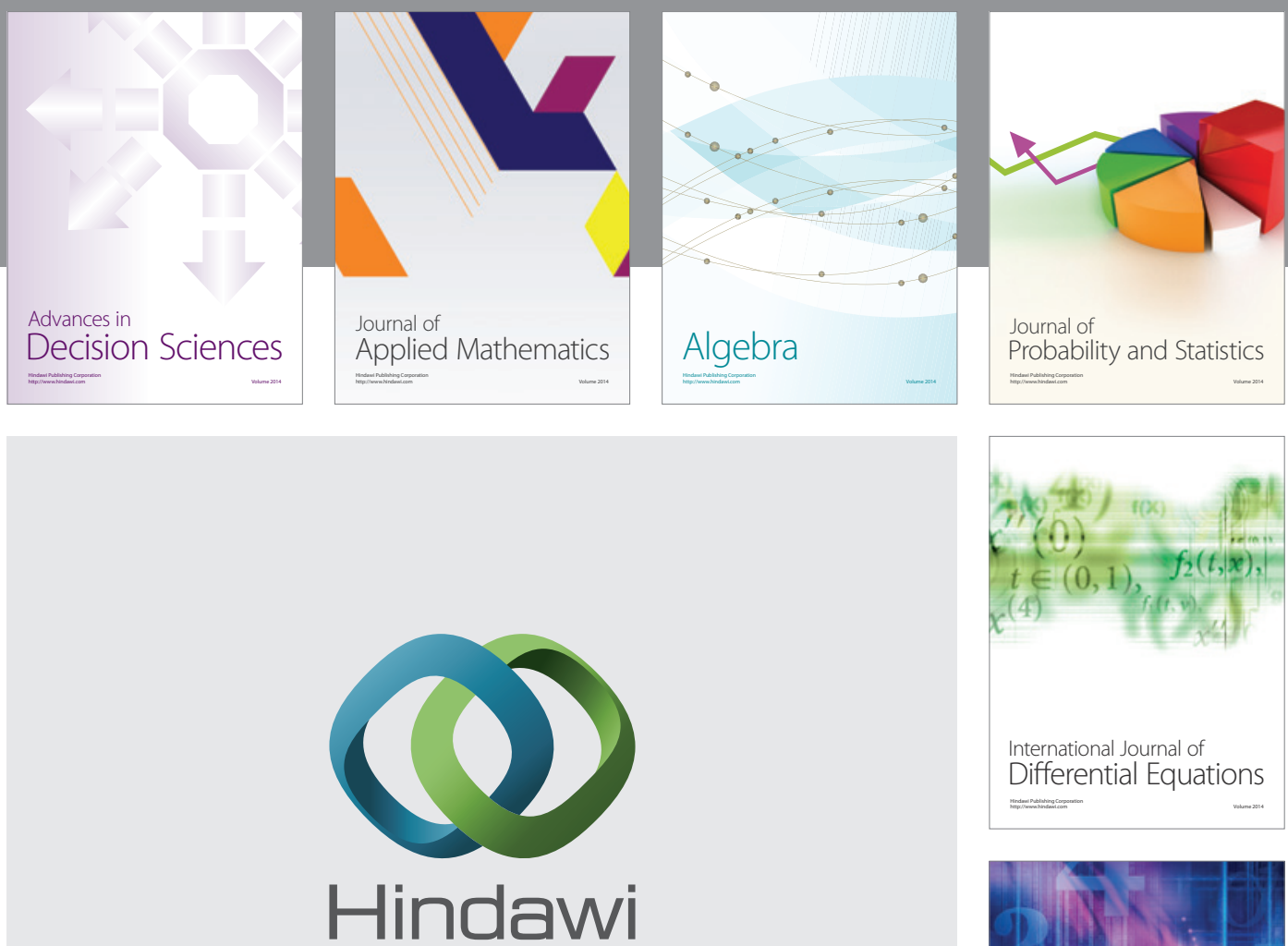

Submit your manuscripts at http://www.hindawi.com
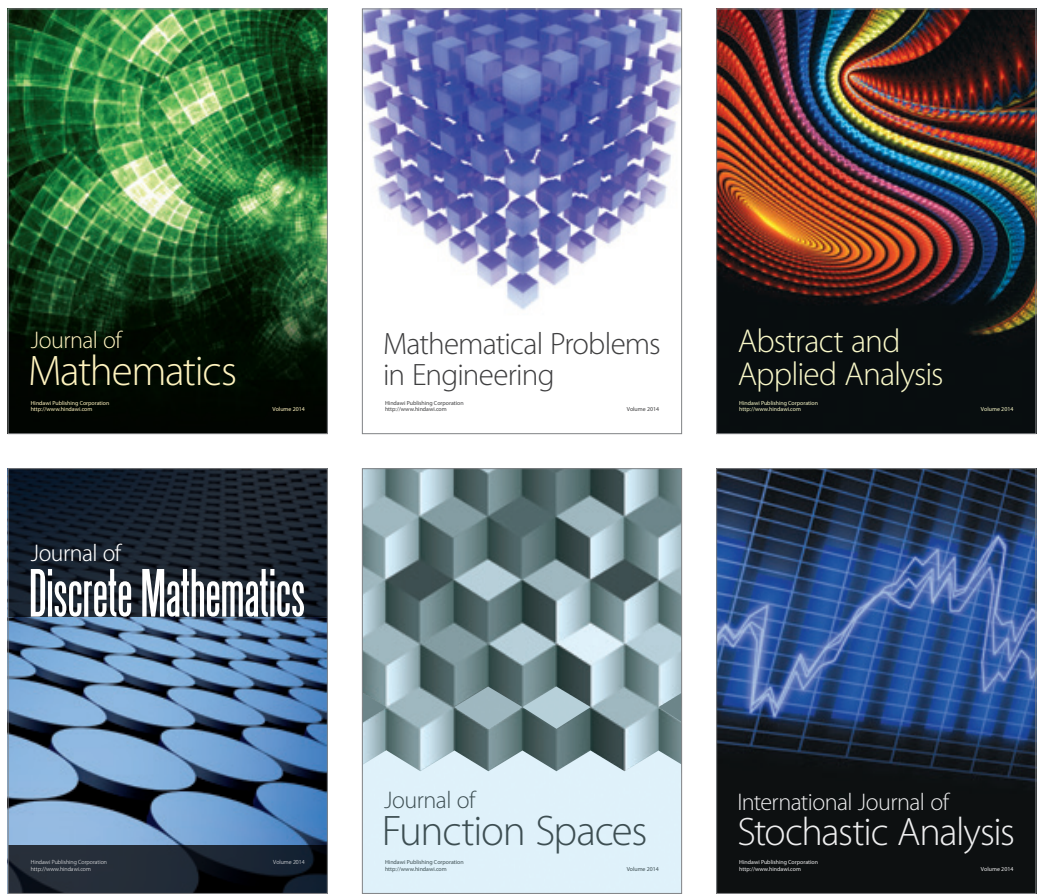

Journal of

Function Spaces

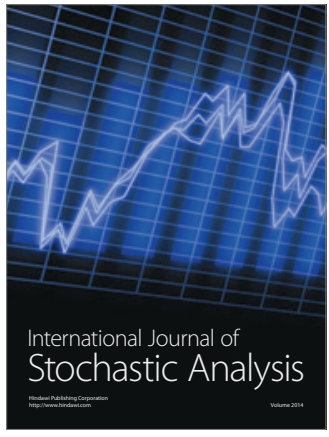

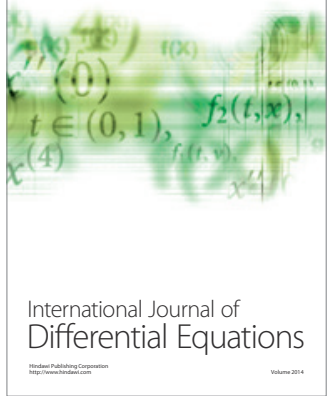
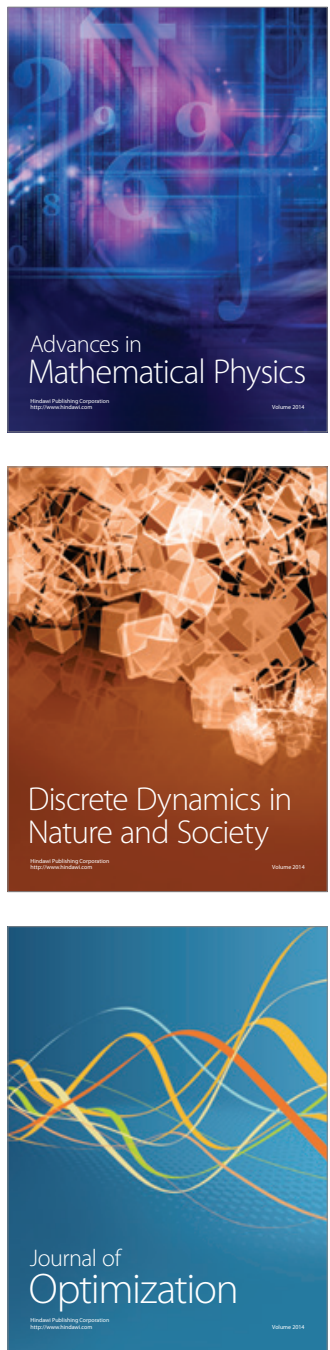